\title{
Summary of effects of parental smoking on the respiratory health of children and implications for research
}

\author{
Derek G Cook, David P Strachan
}

\begin{abstract}
Background-Two recent reviews have assessed the effect of parental smoking on respiratory disease in children.

Methods-The results of the systematic quantitative review published as a series in Thorax are summarised and brought up to date by considering papers appearing on Embase or Medline up to June 1998. The findings are compared with those of the review published recently by the Californian Environmental Protection Agency (EPA). Areas requiring further research are identified.
\end{abstract}

Results-Overall there is a very consistent picture with odds ratios for respiratory illnesses and symptoms and middle ear disease of between $\mathbf{1 . 2}$ and $\mathbf{1 . 6}$ for either parent smoking, the odds usually being higher in pre-school than in school aged children. For sudden infant death syndrome the odds ratio for maternal smoking is about 2. Significant effects from paternal smoking suggest a role for postnatal exposure to environmental tobacco smoke. Recent publications do not lead us to alter the conclusions of our earlier reviews. While essentially narrative rather than systematic and quantitative, the findings of the Californian EPA review are broadly similar. In addition they have reviewed studies of the effects of environmental tobacco smoke on children with cystic fibrosis and conclude from the limited evidence that there is a strong case for a relationship between parental smoking and admissions to hospital. They also review data from adults of the effects of acute exposure to environmental tobacco smoke under laboratory conditions which suggest acute effects on spirometric parameters rather than on bronchial hyperresponsiveness. It seems likely that such effects are also present in children.

Conclusions-Substantial benefits to children would arise if parents stopped smoking after birth, even if the mother smoked during pregnancy. Policies need to be developed which reduce smoking amongst parents and protect infants and young children from exposure to environmental tobacco smoke. The weight of evidence is such that new prevalence studies are no longer justified. What are needed are studies which allow comparison of the effects of critical periods of exposure to cigarette smoke, particularly in utero, early infancy, and later childhood. Where longitudinal studies are carried out they should be analysed to look at the way in which changes in exposure are related to changes in outcome. Better still would be studies demonstrating reversibility of adverse effects, especially in asthmatic subjects or children with cystic fibrosis.

(Thorax 1999;54:357-366)

Keywords: parental smoking; passive smoking; children

In our series of papers in Thorax we have presented a systematic and quantitative review of the health effects of passive smoking on children's respiratory health including middle ear disease and sudden infant death syndrome..$^{1-8}$ In this paper we (1) summarise the findings of these reviews; (2) comment on papers published since then; (3) compare the findings with a review published by the Californian Environmental Protection Agency $(\mathrm{EPA})^{9} ;(4)$ discuss the advantages and disadvantages of our systematic quantitative approach; (5) discuss possible mechanisms that might explain the epidemiological findings; (6) identify what further research is needed; and (7) consider the public health issues raised.

\section{Summary of findings from Thorax} reviews

Tables 1 and 2 summarise the findings of the Thorax series. Overall there is a very consistent picture with odds ratios for respiratory illnesses and symptoms and middle ear disease of between 1.2 and 1.6 for either parent smoking, the odds usually being higher in pre-school than school aged children and higher for maternal smoking than for paternal smoking. However, for lower respiratory illness in infancy and for wheeze and cough in schoolchildren the effect of paternal smoking in households where the mother did not smoke 
Table 1 Summary of effects of parental smoking on the respiratory health of children

\begin{tabular}{|c|c|c|c|c|}
\hline Outcome & Either parent $O R(95 \% C I)$ & Mother OR (95\% CI) & Father only OR (95\% CI) & Both parents OR (95\% CI) \\
\hline \multicolumn{5}{|c|}{ Lower respiratory illnesses (LRI) at age $0-2$} \\
\hline All studies & $1.57(1.42$ to 1.74$)$ [27] & $1.72(1.55$ to 1.91$)$ [27] & $1.29(1.16$ to 1.44$)[16]$ & \\
\hline Community studies of wheeze & 1.55 (1.16 to 2.08$)[5]$ & $2.08(1.59$ to 2.71$)[7]$ & & \\
\hline $\begin{array}{l}\text { Community studies of LRI, } \\
\text { bronchitis and/or pneumonia }\end{array}$ & $1.54(1.31$ to 1.80$)[11]$ & $1.57(1.33$ to 1.86$)[7]$ & & \\
\hline $\begin{array}{l}\text { Hospital admission for LRI, } \\
\text { bronchitis, bronchiolitis or } \\
\text { pneumonia }\end{array}$ & $1.71(1.21$ to 2.40$)[8]$ & 1.53 (1.25 to 1.86$)[9]$ & $1.32(0.87$ to 2.00$)[6]$ & \\
\hline \multicolumn{5}{|l|}{ Prevalence rates at age $5-16$} \\
\hline Wheeze & $1.24(1.17$ to 1.31$)[30]$ & $1.28(1.19$ to 1.38$)[18]$ & $1.14(1.06$ to 1.23$)[10]$ & 1.47 (1.14 to 1.90$)[11]$ \\
\hline Cough & $1.40(1.27$ to 1.53$)[30]$ & $1.40(1.20$ to 1.64$)[14]$ & $1.21(1.09$ to 1.34$)[9]$ & $1.67(1.48$ to 1.89$)[16]$ \\
\hline Phlegm & 1.35 (1.13 to 1.62$)[6]$ & & & $1.46(1.04$ to 2.05$)[5]$ \\
\hline Breathlessness & $1.31(1.08$ to 1.59$)[6]$ & & & \\
\hline Asthma (cross sectional studies) & $1.21(1.10$ to 1.34$)[21]$ & $1.36(1.20$ to 1.55$)[11]$ & 1.07 (0.92 to 1.24$)[9]$ & $1.50(1.29$ to 1.73$)[8]$ \\
\hline Asthma (case-control studies) & $1.37(1.15$ to 1.64$)[14]$ & & & \\
\hline Bronchial reactivity & & $1.29 \ddagger(1.10$ to 1.50$)[10]$ & & \\
\hline Skin prick positivity & & $0.87^{\star}(0.64$ to 1.24$)[8]$ & & \\
\hline \multicolumn{5}{|l|}{ Incidence of asthma } \\
\hline Under age 6 & & $1.31 \dagger(1.22$ to 1.41$)[4]$ & & \\
\hline Over age 6 & & $1.13+(1.04$ to 1.22$)[4]$ & & \\
\hline \multicolumn{5}{|l|}{ Middle ear disease } \\
\hline Acute otitis media & Range 1.0 to $1.6[8]$ & & & \\
\hline Recurrent otitis media & $1.48(1.08$ to 2.04$)[7]$ & & & \\
\hline Middle ear effusion & $1.38+(1.23$ to 1.55$)[4]$ & & & \\
\hline Referral for glue ear & $1.21 \dagger(0.95$ to 1.53$)[7]$ & & & \\
\hline Sudden infant death & & 2.13 (1.86 to 2.43$)[18]$ & & \\
\hline
\end{tabular}

${ }^{\star}$ Results relate to maternal smoking during pregnancy or exposure to environmental tobacco smoke (ETS) in infancy. Data for ETS exposure during later childhood are too heterogeneous for meta-analysis.

†Based on fixed effects estimate.

$\ddagger$ Relates largely, but not entirely to maternal smoking.

IEstimate and confidence limits differ from those in reference 2 due to exclusion of the study by Bulterys et al (see Erratum at end of this paper).

Numbers in square brackets are numbers of studies on which pooled odds ratios based.

Source of data: references 1-7.

Table 2 Summary of pooled percentage difference (95\% confidence intervals) for effect of parental smoking on lung function

\begin{tabular}{llll}
\hline & $\begin{array}{l}\text { No. of } \\
\text { studies }\end{array}$ & $\begin{array}{l}\text { \% difference }(95 \% \\
\text { CI) fixed effect }\end{array}$ & $\begin{array}{l}\text { \% difference (95\% } \\
\text { CI) random effect }\end{array}$ \\
\hline FVC & 19 & $-0.2(-0.4$ to +0.1$)$ & $-0.4(-0.8$ to +0.0$)$ \\
FEV $_{1}$ & 21 & $-0.9(-1.2$ to -0.7$)$ & $-1.4(-1.9$ to -1.0$)$ \\
MEF & 19 & $-4.8(-5.4$ to -4.3$)$ & $-5.0(-6.6$ to -3.3$)$ \\
EEF & 9 & $-4.3(-5.3$ to -3.3$)$ & $-4.3(-5.5$ to -3.1$)$ \\
\hline
\end{tabular}

$\mathrm{FVC}=$ forced vital capacity $\mathrm{FEV}_{1}=$ forced expiratory volume in one second; $\mathrm{MEF}=$ mid expiratory flow rate; $\mathrm{EEF}=$ end expiratory flow rate.

Source: reference 8 .

was statistically significant. This latter observation suggests that much of the observed association with maternal smoking is probably due to postnatal rather than prenatal (intrauterine) exposure. Because smoking by the mother during pregnancy is almost invariably associated with postnatal smoking, any additional influence of prenatal maternal smoking will be difficult to resolve using epidemiological studies. Except for sudden infant death syndrome (SIDS), the risks associated with parental smoking were largely independent of measured confounding variables, which suggests that residual confounding by unmeasured factors is unlikely to be important.

In June 1998 we re-ran our original search strategy to identify publications since April 1997; this identified 29 articles containing data not included in the original reviews. These are commented on separately in the relevant sections, but the quantitative meta-analyses have not been updated.

Below we summarise the papers published since our original reviews and consider whether any changes in our conclusions are warranted.
LOWER RESPIRATORY ILLNESSES IN INFANCY AND EARLY CHILDHOOD

Two studies published recently from North Carolina, USA, ${ }^{10}$ and Norway ${ }^{11}$ are broadly consistent with our conclusions, although in one $^{11}$ the dose-response gradient was more convincing for smoking by the father than for maternal smoking.

PREVALENCE OF ASTHMA AND RESPIRATORY SYMPTOMS IN SCHOOL AGED CHILDREN Previously $^{3}$ we concluded that there was convincing evidence that parental smoking is associated with increased prevalence of asthma and respiratory symptoms in schoolchildren. Among children with established asthma, parental smoking was associated with more severe disease. A number of cross-sectional studies have been published since our original review, all broadly supporting our conclusions. ${ }^{12-16}$ In a methodological study which compared parental reports of nocturnal cough with overnight recording, smoking parents were found to substantially underreport compared with non-smoking parents, resulting in underestimation of the odds ratio relating cough to exposure to environmental tobacco smoke (ETS). ${ }^{17}$

Few studies published before 1997 provided the information required to compare critical periods of exposure or the effects of smoking by the mother during or after pregnancy. On balance, our earlier review suggested that the prevalence of respiratory symptoms in schoolchildren is related more closely to current maternal smoking than to past smoking by the mother, but the retrospective nature of the early exposure data did not allow firm conclusions to be drawn.

More recently three studies have been published comparing current with past expo- 
sure, with inconsistent findings. A study of 1129 Polish children found upper and lower respiratory infections were related more strongly to current exposure to ETS than to maternal smoking during pregnancy. ${ }^{18} \mathrm{~A}$ second study of 705 fifth grade children in Chicago found that maternal smoking in pregnancy was more strongly related to doctor diagnosed asthma than current maternal smoking. ${ }^{19}$ However, it is worth noting that wheezing was inversely associated with current maternal smoking in this study. Consistent with the Chicago study, a large Scandinavian survey of 15962 children aged 6-12 years in the past year reported that asthma attacks, dry cough and asthma treatment were inversely associated with current smoking in the home but positively associated with smoking in the home in the first two years of life. ${ }^{20}$ Again the lack of an association with current exposure is in contrast to the rest of the literature, and the authors suggest that avoidance of risk factors by parents of symptomatic children is likely to be important. Further studies are needed to clarify this potentially important issue.

INCIDENCE OF ASTHMA AND WHEEZING ILLNESSES The relationship between common lower respiratory illnesses of infancy and asthma in later childhood remains a subject of uncertainty and debate. For this reason we analysed early wheezing illnesses (during the first one or two years of life) separately from the incidence of asthma over a longer period or later in childhood.

Taken together, the evidence suggests that parental smoking is more influential as a cause of early "wheezy bronchitis" than of later onset "asthma". ${ }^{1}$ No new references were identified which further informed this issue. However, one recently published paper ${ }^{21}$ suggests that Norwegian teenagers with asthmatic symptoms are less likely to receive a diagnosis of asthma if their parents smoke. This finding may not be generalisable to other countries and cultures, but it raises the possibility that the association of ETS with asthma may have been underestimated in studies which rely on physician diagnosis.

NATURAL HISTORY AND SEVERITY OF ASTHMA AND WHEEZING

In our original review we found an inconsistent picture relating ETS exposure to prognosis. ${ }^{6}$ Early prognosis appeared to be worse if parents smoked, whereas persistence of symptoms into the teens and twenties was less common in children of smokers. A recently published follow up study of 101 wheezy Swedish infants $^{22}$ is intermediate between these two groups of studies. The presence of asthma at age 10 was more common in children exposed to household smoking in infancy ( $82 \%$ versus $59 \%$ ) although it was not associated with household smoking at age $10(54 \%$ versus $52 \%)$, perhaps reflecting changes in parental behaviour associated with persistence of the child's asthma.

The results of 10 case series addressing asthma severity were more consistent with symptom scores, attack frequency, medication use, admissions to hospital, and life threatening attacks being generally positively related to ETS exposure. ${ }^{6}$ No new references were identified to change this conclusion.

\section{ALLERGIC SENSITISATION}

In contrast to previous reviews, we concluded that the balance of evidence did not support a positive association of allergic sensitisation with parental smoking, either before or after birth. ${ }^{5}$ One reason for this discrepancy is that many reviews included asthma and wheezing which may be related to exposure to ETS by mechanisms other than allergy. We chose to review 36 studies of IgE, skin prick positivity, hay fever, or eczema separately from studies of asthma in order to address more directly the influence of exposure to ETS on allergic sensitisation. There was only limited scope here for meta-analysis, with inconsistency in the quantitative results.

Four more recent publications have contributed information in relation to eczema. Three of these, from Denmark, Britain and Hong Kong, show a slightly reduced risk among the offspring of smokers, ${ }^{1323} 24$ and a fourth from Germany $^{25}$ found an increased risk cross sectionally which was not sustained on follow up. A British study of skin prick tests among infants of atopic parents ${ }^{26}$ reported an inverse association of prick positivity with maternal smoking while a Swedish study also reported a weak inverse association between prick positivity and maternal smoking. ${ }^{14}$ These results are consistent with a significantly reduced prevalence of hay fever among the children of smokers in two national British birth cohorts, ${ }^{24}$ but not with the slightly raised risk of hay fever in the survey from Hong Kong. ${ }^{13}$ These additional publications do not lead us to alter the conclusion of our earlier review.

\section{BRONCHIAL REACTIVITY}

Our meta-analysis of the relationship between bronchial reactivity (BHR), as assessed by challenge tests, and exposure to ETS (largely maternal smoking) in 10 population samples suggests a small but real increase in BHR amongst the children of smoking mothers (OR $1.29,95 \%$ CI 1.10 to 1.50$).{ }^{7}$ However, it seems likely that this estimate is biased upwards since other studies providing $\mathrm{p}$ values but not odds ratios appear to be generally negative, while four studies have collected data but have not been published. The published data relating ETS exposure to bronchial reactivity are therefore not definitive; $60 \%$ of all potentially relevant data relating to the issue are either not published or are in papers providing no effect measures. Our literature update identified only one small study of 182 Italian children but no data were presented relating ETS to $\mathrm{BHR}^{27}$ The current uncertainty could be resolved by pooling data from all these studies to provide an unbiased estimate of the association.

SPIROMETRIC INDICES

In our earlier review we concluded that maternal smoking is associated with small but statis- 
tically significant deficits in forced expiratory volume in one second $\left(\mathrm{FEV}_{1}\right)$ and other spirometric indices in school aged children (table 2). ${ }^{8}$ This is almost certainly a causal relationship. Much of the effect may be due to maternal smoking during pregnancy which appears to have rather larger effects on neonatal lung mechanics, with the small effects seen in school aged children being attributable to the residual effects of smoking in pregnancy. The effect of the latter is reinforced by a recent Norwegian study of 803 infants in whom tidal flow-volume loops, compliance and resistance were measured 2.7 days after birth. ${ }^{28}$ However, the magnitude of effects seems rather smaller in this study than in the earlier studies.

In addition, it is likely that susceptible individuals will experience acute reductions in $\mathrm{FEV}_{1}$ and peak expiratory flow (PEF) when exposed to ETS. ${ }^{7}$ Further work is needed to establish this. It seems likely that the small differences in lung function in children associated with maternal smoking will translate into small differences in adults. Such subtle reductions are unlikely to impact on rates of development of chronic airflow obstruction unless evidence emerges that children exposed to cigarette smoke in early life have faster rates of lung function decline in adult life. In a recent metaanalysis of cross sectional adult data we found a $2.6 \%$ deficit in $\mathrm{FEV}_{1}$ in non-smoking adults exposed to ETS, very similar to the effect reported in children. ${ }^{29}$

Further evidence that exposure to ETS may have some effects on lung function comes from cohort studies. Of the six cohort studies, the Six Cities Study is an order of magnitude larger than any other cohort and thus deserves substantial weight. It reported very small but statistically significant effects of maternal smoking on lung growth $(-3.8 \mathrm{ml} /$ year for $\mathrm{FEV}_{1}$ ).

To determine whether effects are reversible also requires evidence from cohort rather than cross sectional studies. Unfortunately none of the longitudinal studies have looked at changes in lung function in relation to changes in exposure. It would be an advantage if such studies assessed exposure by measuring cotinine levels. This would take account of changes in exposure to ETS which occur as children grow older and spend less time with their parents resulting in a reduction in their exposure to ETS even though parental smoking habits remain constant. Sources of ETS outside the home may become important, particularly during teenage years.

SUDDEN INFANT DEATH SYNDROME (SIDS)

Unlike other areas, adjustment for confounding variables was important when looking at SIDS. ${ }^{2}$ However, an adjusted odds ratio of 2 is difficult to attribute to residual confounding and convincing evidence of dose-response provide further evidence for a causal relationship. Our conclusions differed from most previous reviews in focusing on the relative importance of maternal smoking during pregnancy rather than postnatal exposure to ETS as an explanation for the raised risks. Based on the limited available evidence where mothers claimed to be non-smokers, we concluded that postnatal exposure plays an important role. Recent studies support our interpretation (see below), though none have yet used measurements of cotinine levels to validate maternal nonsmoking status.

Four recently published studies (three case-control ${ }^{30-32}$ and one nested case-control ${ }^{33}$ ) containing new data provide further confirmation of the effects of maternal smoking on SIDS. The Munster study provides clear evidence of a dose-response in relation to maternal smoking during pregnancy and of the importance of controlling for confounding variables $^{31}$ while the Nordic SIDS study reported only unadjusted odds ratios for maternal smoking in pregnancy. ${ }^{30}$ Further data from the New Zealand nested case-control study after their national campaign to prevent SIDS reported a univariate odds ratio for paternal smoking where the mother was a nonsmoker of $1.54(95 \% \text { CI } 0.67 \text { to } 3.45)^{33}$ while a Scottish study reported a multivariate odds ratio for father only smoking of 2.12 (95\% CI 0.99 to 4.55$).^{32} \mathrm{~A}$ fifth paper re-analysing data from the US and Sweden presents clear evidence that the odds ratio for maternal smoking is little affected by adjustment for birth weight. ${ }^{34}$

\section{MIDDLE EAR DISEASE}

Studies of middle ear disease were of various designs including cohort studies, case-control studies, and population surveys. They were reviewed in four groups: 13 studies of acute otitis media, nine of recurrent otitis media, five of middle ear effusion, and nine of glue ear surgery. ${ }^{4}$ A meta-analysis was possible for all outcomes except acute otitis media, and the results were consistent with pooled odds ratios in the range 1.2-1.5 (table 1).

Four more recently published case-control studies from Canada, ${ }^{35}$ Sweden, ${ }^{36}$ Malaysia, ${ }^{37}$ and Minnesota, USA ${ }^{38}$ present quantitative data for acute or chronic otitis media in relation to parental smoking. The $95 \%$ confidence intervals for the odds ratios overlap with the pooled values derived in our meta-analyses. A detailed longitudinal study of 2253 infants in Pennsylvania, $\mathrm{USA}^{39}$ assessed the presence of middle ear effusion clinically and by tympanometry at monthly intervals throughout the first two years of life. There was a highly significant positive association between the duration of effusion and the number of smokers in the household during both the first and second years of life. Although these results cannot be compared directly with odds ratios derived in other studies, they are qualitatively consistent with our earlier meta-analyses.

Comparison with Californian EPA review Table 3 contrasts the methods used in our Thorax reviews and those of the Californian Environmental Protection Agency ${ }^{90}$ and table 4 summarises the conclusions of the Californian review. Despite the different approach the conclusions are qualitatively and, from a public health perspective, very similar. The main 
Table 3 Comparison of methods used in Thorax series and Californian EPA reviews

\begin{tabular}{|c|c|c|}
\hline & Thorax series & Californian EPA \\
\hline General approach & $\begin{array}{l}\text { Systematic search of the } \\
\text { literature }\end{array}$ & Update of previous EPA review \\
\hline \multirow[t]{2}{*}{ Scope } & Children only & All ages \\
\hline & $\begin{array}{l}\text { Respiratory (including SIDS but } \\
\text { not CF) }\end{array}$ & $\begin{array}{l}\text { All systems (including SIDS, } \\
\text { respiratory and CF) }\end{array}$ \\
\hline Inclusions and exclusions & $\begin{array}{l}\text { Emphasis on groups of similar } \\
\text { studies }\end{array}$ & $\begin{array}{l}\text { Inclusion of all, even isolated } \\
\text { studies }\end{array}$ \\
\hline Disease definition & Specific outcomes distinguished & Broader groups of diseases \\
\hline $\begin{array}{l}\text { Community versus } \\
\text { hospital }\end{array}$ & Distinguished where possible & Usually combined \\
\hline $\begin{array}{l}\text { Maternal and paternal } \\
\text { smoking }\end{array}$ & Distinguished where possible & Rarely analysed separately \\
\hline $\begin{array}{l}\text { Prenatal and postnatal } \\
\text { exposure }\end{array}$ & Rarely possible to distinguish & Rarely possible to distinguish \\
\hline Confounding & $\begin{array}{l}\text { Addressed in meta-analysis } \\
\text { where possible }\end{array}$ & Discussed in text \\
\hline Publication bias & $\begin{array}{l}\text { Discussed and evaluated where } \\
\text { possible }\end{array}$ & Not discussed \\
\hline Summarisation & $\begin{array}{l}\text { Emphasis on meta-analysis, less } \\
\text { narrative }\end{array}$ & $\begin{array}{l}\text { More narrative, selective use of } \\
\text { meta-analysis }\end{array}$ \\
\hline Causal inference & Discussed & Discussed \\
\hline $\begin{array}{l}\text { Population attributable } \\
\text { risk estimates }\end{array}$ & Not attempted & $\begin{array}{l}\text { Included for USA and } \\
\text { California }\end{array}$ \\
\hline $\begin{array}{l}\text { Experimental (chamber) } \\
\text { studies }\end{array}$ & $\begin{array}{l}\text { Very limited evidence in } \\
\text { children }\end{array}$ & $\begin{array}{l}\text { Limited evidence, mainly in } \\
\text { adults }\end{array}$ \\
\hline Mechanisms & Not discussed & Discussed \\
\hline
\end{tabular}

SIDS = sudden infant death syndrome; $\mathrm{CF}=$ cystic fibrosis

${ }^{\star}$ Only used for asthma induction, including early wheezing illnesses.

differences are a difference in interpretation of the inconsistent data on allergic sensitisation (we hold by our view that allergic sensitisation is not related to in utero or ETS exposure) and greater emphasis in the Californian review on the relationship between exposure to ETS and the incidence of asthma. This arises because the Californian review includes prevalence studies in its assessment of incidence, and also because there is no clear distinction between the incidence of lower respiratory infections and wheezing illness in infancy and the development of later onset asthma.

CYSTIC FIBROSIS

We did not evaluate the effects of ETS on children with cystic fibrosis in our Thorax series because there were insufficient studies for a quantitative review. However, the Californian EPA review ${ }^{9}$ summarises five studies relating the severity of cystic fibrosis to parental smoking. ${ }^{41-44}$ Over half of the children in these studies were exposed to ETS. Hospital admissions for cystic fibrosis exacerbations were sig- nificantly related to parental smoking in three of the four studies which reported this association, and in the same three studies exposure to ETS was significantly related to other measures of disease severity. The studies are inconsistent or inconclusive in relation to the effects of parental smoking on growth and ventilatory function.

\section{Value of a systematic quantitative approach}

At the end of this series it is worth considering the value of the approach we took to reviewing the evidence. Meta-analyses of observational studies raise a number of difficulties compared with randomised controlled trials. ${ }^{45}$ Indeed, some have argued that "the meta-analysis of published non-experimental data should be abandoned". ${ }^{46}$ Shapiro argues that metaanalysis is popular because it offers the Holy Grail of attaining statistically stable estimates for effects of low magnitude. This is dangerous, he argues, because, where many studies produce only modest increases in risk, those increases may be due to the same biases in all the studies. In our own case only the twofold increase in the risk of SIDS and possibly lower respiratory infection in infancy are large enough to make confounding unlikely when the relative risk is considered in isolation. However, the approach we adopted of comparing unadjusted and adjusted relative risks in each study permits a more comprehensive evaluation of confounding effects. Although this does not address the possibility of a bias common to all studies, the latter is unlikely if there is consistency of evidence from studies of different design and locations. While such dangers exist, it would seem even more dangerous to rely on a single large study or on narrative reviews. In our view the presentation of all studies on a single graph is an extremely valuable summary of the evidence, even where heterogeneity in effects is so large as to render meta-analysis irrelevant. It is a separate argument to decide whether residual confounding in all studies may explain the findings. Undoubtedly the definitive demonstration of

Table 4 Summary of results and conclusions of Californian EPA review

\begin{tabular}{|c|c|c|}
\hline Outcome & Odds ratios & Conclusions \\
\hline $\begin{array}{l}\text { Lower respiratory disease } \\
\text { in young children }\end{array}$ & $1.5-2$ & $\begin{array}{l}\text { ETS exposure clearly confers an increased risk of acute lower } \\
\text { respiratory disease in young children }\end{array}$ \\
\hline Asthma "induction"» & $\begin{array}{l}1.75-2.25 \text { in summary }(n=37) \\
R R=1.45 \text { for household exposure, } \\
R R=1.6 \text { for maternal smoking }\end{array}$ & Compelling evidence of an effect \\
\hline Asthma exacerbation & Narrative & Disease severity increased by ETS \\
\hline $\begin{array}{l}\text { Respiratory symptoms in } \\
\text { children }\end{array}$ & Narrative & Associated with parental smoking \\
\hline $\begin{array}{l}\text { Lung growth and } \\
\text { development }\end{array}$ & Narrative & Evidence not wholly consistent but suggestive of small effects \\
\hline Atopy & Narrative & $\begin{array}{l}\text { Several studies have shown an increased risk of atopy in } \\
\text { children of smoking mothers, though the evidence regarding } \\
\text { this issue is mixed }\end{array}$ \\
\hline Middle ear infection & Narrative; OR $=1.62$ & Risk of both acute and chronic middle ear infection increased \\
\hline Sudden infant death & Narrative & $\begin{array}{l}\text { Adequate epidemiological evidence of a causal relationship } \\
\text { between maternal smoking and SIDS. Compelling evidence } \\
\text { that postnatal ETS exposure is an independent risk factor }\end{array}$ \\
\hline
\end{tabular}

ETS $=$ environmental tobacco smoke; SIDS = sudden infant death syndrome.

* Some of the studies included are cross sectional studies of asthma prevalence and thus the conclusion of an effect applies in part to prevalence, not to incidence. Difficult to understand why summary differs from text - in particular from meta-analysis. 
Table 5 Mechanisms proposed for respiratory effects of passive smoking

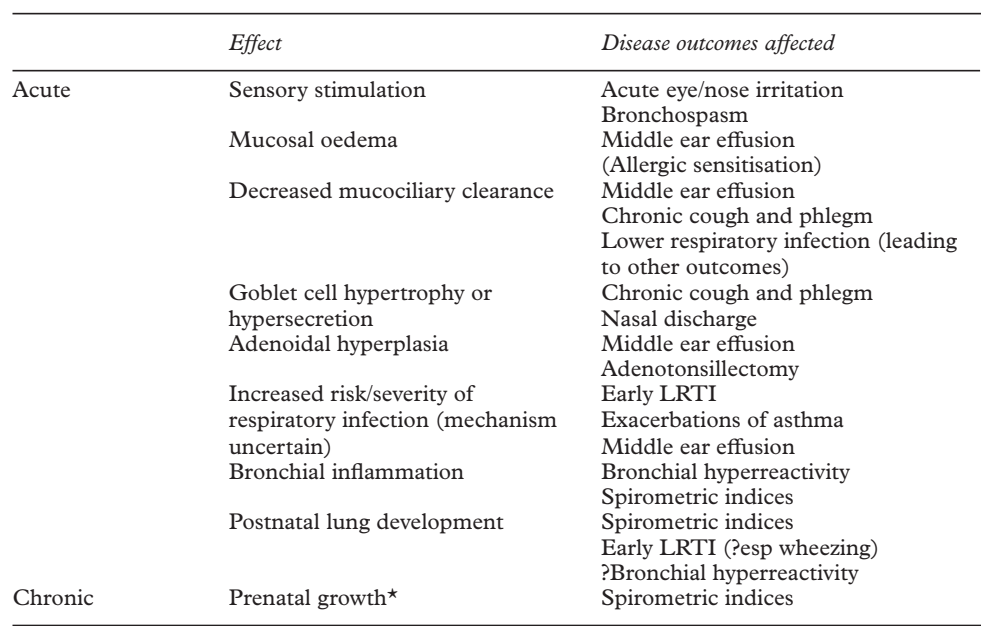

LRTI $=$ lower respiratory tract infection.

${ }^{\star}$ Due to in utero exposure to maternal smoking.

cause and effect requires randomised trials, a point we pick up below.

In our view the major advantage of a systematic quantitative approach is that it has produced a useful corrective to a narrative approach which gives undue weight to highly valued and well published studies. This was particularly valuable in assessing the effect of maternal smoking on allergy. The major disadvantages were the large amount of work needed to extract comparable data and the need to reduce analysis to lowest common denominators. Here the main issue was the variety of ways in which exposure was assessed. Nevertheless, it was possible in most instances to compare maternal with paternal/other household smoking and to gain some insight into dose-response. The effect of adjustment for confounding variables was unimportant except for outcomes other than SIDS. Given the variety of confounders adjusted for and methods of adjustment used, this was fortunate.

Whenever systematic reviews of trials are carried out the quality of studies should be assessed and the sensitivity to inclusion of poor studies investigated. In our reviews the lack of easily agreeable criteria meant we included all studies where possible. For example, response rates were often lowest in some of the "best" studies because they were longitudinal. Equally it was often difficult to extract necessary information from some of the most influential studies, particularly those published early on. Fortunately the consistency of the evidence meant that estimates of effect were little altered by exclusion of specific studies.

It is important not to give undue emphasis to point estimates without considering the consistency and heterogeneity of results lying behind them. For this reason we believe that the figures presenting all studies as well as pooled estimates should be available. This allows distinction of lack of a consistent pattern from statistical heterogeneity where a consistent direction of effect is seen. In our reviews a consistent pattern was seen except for allergic sensitisation. In most instances fixed and random effects estimates were very similar, usually with random slightly greater, while confidence limits for random effects were wider. This reflects the greater emphasis placed on smaller studies by a random effects approach. It is therefore more susceptible to publication bias. In practice, although we were able to detect publication bias for respiratory symptoms and for effects on $\mathrm{FEV}_{1}$ (in both instances small studies tended to show larger effects), the overall picture and estimates were little altered by excluding small studies. ${ }^{3} 8$

\section{Mechanisms}

Evidence relating to mechanisms could potentially assist in interpretation of the epidemiological data we have reviewed. Table 5 summarises the potential mechanisms whereby maternal smoking during pregnancy or exposure to ETS postnatally might influence respiratory disease in children. However, while most of these mechanisms are plausible, remarkably little evidence exists to confirm or refute them. ${ }^{9}$

The most direct evidence on mechanisms is from acute effects on upper respiratory mucosa $a^{9}$ but, apart from middle ear effusion, this is least relevant to the outcomes we have considered. The most convincing epidemiological evidence relates to early lower respiratory infection in relation to postnatal exposure, yet we are lacking insights into how ETS increases the severity of these early (largely viral) infections.

An early hypothesis was that smoking parents, being more susceptible to respiratory infections themselves, might then transmit them to their children. Thus Colley in two early papers on parental smoking and respiratory symptoms looked at the effect of adjusting for parental phlegm production. ${ }^{47}{ }^{48}$ While adjustment did not adequately explain the higher prevalence rates in children of smoking parents, this hypothesis deserves further consideration in relation to viral infections.

Studies in children which have assessed the effects of acute exposure to ETS in controlled situations are very limited, but there are weak suggestions of acute effects of ETS exposure on lung function. ${ }^{7}$ The more extensive evidence in adults has recently been reviewed. ${ }^{9}{ }^{49}$ Coultas ${ }^{49}$ reported that "most of the ETS inhalation chamber studies show slight to moderate transient effects on lung function in at least some of the study subjects. In several studies participants experienced decrements in lung function exceeding 20\%." Such acute effects might well explain the greater peak flow variability in children of smoking parents. ${ }^{7}$ Further studies to confirm these findings in children seem warranted.

The limited evidence relating ETS to bronchial inflammation and airway development is only by extrapolation from active smokers or from sidestream exposure of laboratory animals. Our review has effectively excluded allergic sensitisation as a link between ETS and asthma and casts some doubt on the $\mathrm{BHR}$ route. Evidence of acute effects on BHR in chamber studies in adults is limited and not consistent. $^{9}$ 
Outstanding research issues

While the accumulated evidence for adverse effects of parental smoking on the respiratory health of children is very strong, it is based almost entirely on observational studies. There is no clear demonstration of the effect of reducing exposure. Such studies are needed, either in the form of randomised controlled trials or as observational studies focusing on parents who change their smoking habit.

While randomised controlled trials are the ideal, they would need to be large. Consider a study in which it was proposed to reduce smoking in parents of children with middle ear effusion with the outcome of interest being operative treatment. Middle ear effusion commonly resolves in about one third of cases between outpatient referral and operative treatment some 3-6 months later. We might expect perhaps $10 \%$ of parents to stop smoking with usual care and might hope to double this to $20 \%$ in the intervention group. Assuming one third of cases resolved spontaneously in children of smokers and an optimistic one half in children of those who quit smoking, we would need to randomise 33500 children overall (16 750 to each group) to have $90 \%$ power at the 0.05 significance level. This is because the majority of parents in each group continue to smoke. The difference in outcome between the intervention and usual care groups is therefore small and the trial needs to be large to detect such a difference. Such considerations explain why there have been so few trials and those that have been carried out have been negative when analysed on an intention to treat basis.

It seems unlikely that many randomised controlled trials will take place. Nevertheless, observational studies looking at changes in health outcome in relation to changes in exposure would be valuable. For example, it would be possible to compare the outcomes in the children of the usual care group comparing the $90 \%$ whose parents continued to smoke with the children of the $10 \%$ whose parents quit. For such an analysis a sample of only 1000 would suffice.

Further cross sectional studies of lung function or symptoms are unlikely to be informative unless they can compare critical periods of exposure or look at changes in parental smoking-for example, school age versus exposure during pregnancy or early infancy for symptoms, or prenatal versus postnatal exposure for SIDS.

Future studies need to give thought to the assessment of exposure. Key issues are distinguishing between maternal and paternal smoking and looking for dose-response. Objective measures such as cotinine levels are important since actual exposure will vary between individuals and tend to decrease with age despite parental smoking habits being constant. It is also important to consider whether children from non-smoking families are a suitable group to treat as non-exposed. Any background exposure in this group which has an effect on respiratory disease will bias any comparisons between smoking and non-smoking families towards the null hypothesis of no difference. Measurement of cotinine levels will help here. The limited evidence available is not entirely consistent. Studies in British children suggest that the low levels of exposure seen in non-smoking households ${ }^{50}$ do not influence either lung function or respiratory symptoms. ${ }^{51}{ }^{52}$ In contrast, an Italian study has reported effects on lung function in children with occasional exposure to ETS. ${ }^{53}$ However, the cotinine levels reported in this study are extremely high, even for children from nonsmoking households.

Further studies distinguishing current versus cumulative versus early (particularly in utero) exposure in relation to symptoms and lung function would help to elucidate the mechanism and inform preventive measures. While maternal smoking is the most important source of exposure in many countries, it would be valuable to see further large studies measuring dose where mothers are confirmed nonsmokers. The studies from China ${ }^{54-57}$ have been particularly useful in this context. In the case-control studies of SIDS it would be important to confirm non-smoking status of mothers at interview by measurement of salivary cotinine levels. Such an approach would remove worries about reporting bias.

There is undoubtedly a need to clarify the association between exposure to ETS and BHR - here the solution would be to pool data from all studies published and unpublished. Equally, with only four published studies of peak flow variability there is undoubtedly room for publication bias. However, if there is an acute effect on lung function from ETS exposure in at least a significant minority of subjects this will be better shown by laboratory studies of acute exposure.

Finally, it would be useful to have larger and more comprehensive studies of children with cystic fibrosis. In particular, there is a need for studies of prognosis and severity.

The magnitude of the problem: attributable risks

Throughout our review series we focused on odds ratios as measures of effect since these are what studies provide and they are portable in that studies from different countries produce similar estimates. However, it is important to consider the potential size of the public health problem in any given country and the difference in absolute terms of the different health effects should be recognised. Previous reports have done this for the USA ${ }^{58}$ and for California. ${ }^{9}$ Such analyses involve a number of assumptions which may be split into two stages. At the first stage the percentage of cases in a population attributable to an exposure (PAR\%) can be derived from knowledge of the relative risk (RR) and the proportion of subjects exposed in a population (p):

$$
\mathrm{PAR} \%=\frac{\mathrm{p}(\mathrm{RR}-1) \times 100}{1+\mathrm{p}(\mathrm{RR}-1)}
$$

The PAR $\%$ for a range of relative risks and exposure prevalence rates is given in table 6 . 
Table 6 Population attributable risk percentages for a range of relative risks and exposure prevalence rates

\begin{tabular}{lrrrrrrr}
\hline \multirow{2}{*}{$\begin{array}{l}\text { Relative } \\
\text { risk }\end{array}$} & \multicolumn{7}{l}{ Prevalence of smoking exposure } \\
\cline { 2 - 8 } & 0.2 & 0.25 & 0.3 & 0.35 & 0.4 & 0.45 & 0.5 \\
\hline 1.1 & 2 & 2 & 3 & 3 & 4 & 4 & 5 \\
1.2 & 4 & 5 & 6 & 7 & 7 & 8 & 9 \\
1.3 & 6 & 7 & 8 & 10 & 11 & 12 & 13 \\
1.4 & 7 & 9 & 11 & 12 & 14 & 15 & 17 \\
1.5 & 9 & 11 & 13 & 15 & 17 & 18 & 20 \\
1.6 & 11 & 13 & 15 & 17 & 19 & 21 & 23 \\
1.7 & 12 & 15 & 17 & 20 & 22 & 24 & 26 \\
1.8 & 14 & 17 & 19 & 22 & 24 & 26 & 29 \\
1.9 & 15 & 18 & 21 & 24 & 26 & 29 & 31 \\
2 & 17 & 20 & 23 & 26 & 29 & 31 & 33 \\
\hline
\end{tabular}

For our purposes we assume that the odds ratios in table 1 are equivalent to relative risks. Where the number of events is known it is then straightforward to move to the second stage to work out the number of cases attributable to the exposure.

Thus, for SIDS, assuming that $25 \%$ of women smoke during pregnancy and that this raises the risk of sudden infant death by 2, 20\% of deaths from SIDS may be attributed to exposure to ETS (table 6). In England and Wales there are approximately 400 SIDS deaths per year ${ }^{59}$ and thus 80 deaths are attributable to maternal smoking. This may be an underestimate as rather more women smoke postnatally and it takes no account of smoking by other household members. One recent study estimated that $63 \%$ of sudden infant deaths were attributable to parental smoking, ${ }^{60}$ the high percentage arising from a combination of a high relative risk estimate in that study along with an assumption that paternal smoking had a marked effect, thereby increasing the exposure prevalence.

In contrast to sudden infant death which is a fatal but rare condition, lower respiratory infection in infancy, respiratory symptoms in older children, and middle ear disease are much more common but it is difficult to estimate the prevalence of them with any precision. While the number of attributable cases is not easily quantified, even a small relative excess implies many thousands of extra children affected by each of these conditions. The effects range from the very minor to major, and from acute to chronic. Thus, assuming a relative risk of 1.3 and a prevalence exposure of $35 \%$, about $10 \%$ of surgical operations for glue ear are attributable to the effects of parental smoking. Given the reported 60000 operations per year in England, ${ }^{61}$ this amounts to an extra 6000 ear operations per year. The number of attributable episodes of glue ear will be far greater.

\section{Public health issues}

That exposure to cigarette smoke after childbirth, rather than solely during pregnancy, increases the risk of a range of respiratory problems in infancy as well as later in childhood, appears to alter the agenda. It broadens the problem from maternal smoking to that of family and friends, and hence policy about smoking on public transport, in restaurants, and other public places becomes an important issue. On the other hand, postnatal exposure should be easier to modify as it is theoretically feasible to keep the infant physically apart from the smoker. In practice this is difficult in pre-school children where the mother is a smoker. In particular, it would be wrong to lose sight of the fact that the major part of ETS exposure occurs within the home and that maternal smoking remains the major source in many countries. It seems likely that prevention will remain focused on reducing the percentage of parents who smoke rather than on isolating smokers or increasing ventilation.

ETS pollution is increasingly being tackled in western countries by health promotion campaigns and restrictive interventions - for example, in the workplace. However, few campaigns outside the USA have highlighted the susceptibility of children to ETS exposure. The challenge is to get the message about smoking and health risks in infancy across without making the first six postpartum months even more difficult. While in developed countries "back to sleep" campaigns have successfully altered the sleeping position of babies, smoking rates have been left virtually unchanged. In many undeveloped countries few women smoke, while male smoking rates are very high. It is likely to prove difficult to promote household changes in these groups if education is channelled through mothers because of marked imbalances of power within the family.

It is also important to view the adverse health effects from ETS exposure in context. The effects are small relative to effects of active smoking, but for children ETS exposure is not voluntary. Potentially, the link between parental smoking and uptake of active smoking by their children is of greater long term importance to a child's health. In England parental smoking doubles the risk of smoking uptake by children ${ }^{62}$ which, since $50 \%$ of children come from smoking households, allows us to estimate that up to one third of children who smoke can be attributed to parental example. For this reason, reduction of parental smoking throughout a child's upbringing, rather than just in the perinatal period, may pay substantial future dividends in the prevention of respiratory diseases.

The Department of Health commissioned the reviews on which this article is based. The views expressed are those of the authors and are not necessarily those of the Department of Health. We are indebted to Jenny Taylor and Claire Chazot for their diligent are indebted to Jenny Taylor and Claire Chazot for their diligent
work in assembling the relevant literature, and to Ross Anderson work in assembling the relevant for their part in the reviews of sudden infant and Iain Carey for their part in the reviews of sudden infant
death syndrome and spirometry.

1 Strachan DP, Cook DG. Health effects of passive smoking. 1. Parental smoking and lower respiratory illness in infancy and early childhood. Thorax 1997;52:905-14.

2 Anderson HR, Cook DG. Health effects of passive smoking. 2. Passive smoking and sudden infant death syndrome. Review of the epidemiological evidence. Thorax 1997;52: 1003-9.

3 Cook DG, Strachan DP. Health effects of passive smoking. 3. Parental smoking and respiratory symptoms in schoolchildren. Thorax 1997;52:1081-94.

4 Strachan DP, Cook DG. Health effects of passive smoking. 4. Parental smoking, middle ear disease and adenotonsillectomy in children. Thorax 1998;53:50-6.

5 Strachan DP, Cook DG. Health effects of passive smoking. 5. Parental smoking and allergic sensitisation in children. Thorax 1998;53:117-23.

6 Strachan DP, Cook DG. Health effects of passive smoking. 6. Parental smoking and childhood asthma: longitudinal and case-control studies. Thorax 1998;53:204-12. 
7 Cook DG, Strachan DP. Health effects of passive smoking. 7. Parental smoking bronchial reactivity and peak flow variability in children. Thorax 1998;53:295-301.

8 Cook DG, Strachan DP, Carey IM. Health effects of passive smoking. 9. Parental smoking and spirometric indices in children. Thorax 1998;53:884-93.

9 Dunn A, Zeise L, eds. Health effects of exposure to environmental tobacco smoke. California Environmental Protection Agency, 1997.

10 Margolis PA, Keyes LL, Greenberg RA, et al. Urinary cotinine and parent history (questionnaire) as indicators of passive smoking and predictors of lower respiratory illness in infants. Pediatr Pulmonol 1997; 23:417-23.

11 Nafstad P, Kongerud J, Botten G, et al. The role of passive smoking in the development of bronchial obstruction during the first 2 years of life. Epidemiology 1997;8:293-7.

12 Maier WC, Arrighi HM, Morray B, et al. Indoor risk factors for asthma and wheezing among Seattle school children. Environ Health Perspect 1997;105:208-14.

13 Lam TH, Chung SF, Betson CL, et al. Respiratory symptoms due to active and passive smoking in junior secondary school students in Hong Kong. Int $\mathcal{f}$ Epidemiol 1998;27:41-8.

14 Ronmark E, Lundback B, Jonsson E, et al. Asthma, type-1 allergy and related conditions in 7- and 8-year-old children in northern Sweden: prevalence rates and risk factor in northern Sweden: prevalence rate

15 Saraclar Y, Sekerel BE, Kalayci O, et al. Prevalence of asthma symptoms in school children in Ankara, Turkey. Respir Med 1998;92:203-7.

16 Butland BK, Strachan DP, Anderson HR. The home environment and asthma symptoms in childhood: two population based case-control studies 13 years apart. Tho$\operatorname{rax} 1997 ; 52: 618-24$.

17 Dales RE, White J, Bhumgara C, et al. Parental reporting of children's coughing is biased. Eur F Epidemiol 1997;13:5415.

18 Jedrychowski W, Flak E. Maternal smoking during pregnancy and postnatal exposure to environmental tobacco smoke as predisposition factors to acute respiratory smoke as predisposition factors to acute resp
infections. Environ Health Perspect 1997;105:302-6.

$19 \mathrm{Hu}$ FB, Persky V, Flay BR, et al. Prevalence of asthma and wheezing in public schoolchildren: association with maternal smoking during pregnancy. Ann Allergy Asthma Immunol 1997;79:80-4

20 Forsberg B, Pekkanen J, Clench-Aas J, et al. Childhood asthma in four regions in Scandinavia: risk factors and avoidance effects. Int F Epidemiol 1997;26:610-9.

21 Siersted HC, Boldsen J, Hansen HS, et al. Population based study of risk factors for underdiagnosis of asthma in adolescence: Odense schoolchild study. BMF 1998;316: 651-5.

22 Wennergren G, Amark M, Amark K, et al. Wheezing bronchitis reinvestigated at the age of 10 years. Acta Paediatr chitis reinvestigate

23 Olesen AB, Ellingsen AR, Olesen $\mathrm{H}$, et al. Atopic dermatitis and birth factors: historical follow up by record linkage. BMF 1997;314:1003-8.

24 Butland BK, Strachan DP, Lewis S, et al. Investigation into the increase in hay fever and eczema at age 16 observed between the 1958 and 1970 British birth cohorts. BMf 1997;315:717-21.

25 Schafer T, Dirschedl P, Kunz B, et al. Maternal smoking during pregnancy and lactation increases the risk for atopic

26 Burr ML, Merrett TG, Dunstan FD, et al. The development of allergy in high-risk children. Clin Exp Allergy 1997;27: of allergy

27 La Rosa M, Guglielmo F, Ranno C, et al. Effects of industrial air pollution on pulmonary response to methacholine in schoolchildren. Pediatr Asthma Allergy Immuno 1997:11:207-15.

28 Carlsen KL, Jaakkola JK, Nafstad P, et al. In utero exposure to cigarette smoking influences lung function at birth. Eur Respir F 1997;10:1774-9.

29 Carey IM, Cook DG, Strachan DP. The effects of passive smoke exposure assessed by questionnaire and salivary cotinine on lung function in a longitudinal study of adults. Epidemiology 1999; in press.

30 Oyen N, Markestad T, Skaerven R, et al. Combined effects of sleeping position and prenatal risk factors in sudden infant death syndrome: the Nordic Epidemiological SIDS Study. Pediatrics 1997;100:613-21.

31 Schellscheidt J, Ott A, Jorch G. Epidemiological features of sudden infant death after a German intervention campaign in 1992. Eur 7 Pediatr 1997;156:655-60.

32 Brooke H, Gibson A, Tappin D, et al. Case-control study of sudden infant death syndrome in Scotland, 1992-5. BMF 1997:314:1516-20.

33 Mitchell EA, Tuohy PG, Brunt JM, et al. Risk factors for sudden infant death syndrome following the prevention campaign in New Zealand: a prospective study. Pediatric 1997;100:835-40.

34 MacDorman MF, Cnattingius S, Hoffman HJ, et al. Sudden infant death syndrome and smoking in the United States and Sweden. Am f Epidemiol 1997;146:249-57.

35 Adair-Bischoff CE, Sauve RS. Environmental tobacco smoke and middle ear disease in preschool-age children. Arch Pediatr Adolesc Med 1998;152:127-33.

36 Stenstrom C, Ingvarsson L. Otitis-prone children and controls: a study of possible predisposing factors. 2. Physi-
cal findings, frequency of illness, allergy, day care and parental smoking. Acta Oto-Laryngol 1997;117:696-703.
37 Saim A, Saim L, Saim S, et al. Prevalence of otitis media with effusion amongst pre-school children in Malaysia. Int with effusion amongst pre-school children

38 Salazar JC, Daly KA, Giebink GS, et al. Low cord blood pneumococcal immunoglobulin G (IgG) antibodies predict early onset acute otitis media in infancy. Am $\mathcal{f}$ Epidemiol 1997;145:1048-56.

39 Paradise JL, Rockette HE, Colborn DK, et al. Otitis media in 2253 Pittsburgh-area infants: prevalence and risk factors during the first two years of life. Pediatrics 1997;99:318-33.

40 Waller K. Developmental toxicity II: postnatal manifestations. In: Dunn A, Zeise L, eds. Health effects of exposure to environmental tobacco smoke. California Environmental Protection Agency, 1997; 4-1-4-48.

41 Gilljam H, Stenlund C, Ericsson-Hollsing A, et al. Passive smoking in cystic fibrosis. Respir Med 1990;84:289-91.

42 Rubin BK. Exposure of children with cystic fibrosis to environmental tobacco smoke. N Engl f Med 1990;323:782-8.

43 Campbell PW3, Parker RA, Roberts BT, et al. Association of poor clinical status and heavy exposure to tobacco smoke in patients with cystic fibrosis who are homozygous for the F508 deletion. F Pediatr 1992;120:261-4.

44 Smyth A, O'Hea U, Williams G, et al. Passive smoking and impaired lung function in cystic fibrosis. Arch Dis Child 1994;71:353-4

45 Egger M, Schneider M, Smith GD. Spurious precision? Meta-analysis of observational studies. BMf 1998;316: $140-4$.

46 Shapiro S. Meta-analysis/Shmeta-analysis. Am f Epidemiol 1994;140:771-8.

47 Colley JR. Respiratory symptoms in children and parental smoking and phlegm production. BMF 1974;2:201-4.

48 Colley JR, Holland WW, Corkhill RT. Influence of passive smoking and parental phlegm on pneumonia and bronchitis in early childhood. Lancet 1974 ;ii: 1031-4.

49 Coultas DB. Health effects of passive smoking. 8. Passive smoking and risk of adult asthma and COPD: an update. $\operatorname{rax} 1998 ; 53: 381-7$

50 Cook DG, Whincup PH, Jarvis MJ, et al. Passive exposure to tobacco smoke in children aged 5-7: individual, family and community factors. BMF 1994;308:384-9.

51 Cook DG, Whincup PH, Papacosta O, et al. Relation of passive smoking as assessed by salivary cotinine concentration and questionnaire to spirometric indices in children. Thorax 1993;48:14-20.

52 Strachan DP, Jarvis MJ, Feyerabend C. The relationship of salivary cotinine to respiratory symptoms, spirometry, and exercise-induced bronchospasm in seven-year-old children. Am Rev Respir Dis 1990;142:147-51.

53 Corbo GM, Agabiti N, Forastiere F, et al. Lung function in children and adolescents with occasional exposure to environmental tobacco smoke. Am $\mathcal{F}$ Respir Crit Care Med 1996;154:695-700.

54 Chen Y, Li WX. The effect of passive smoking on children's pulmonary function in Shanghai. Am 7 Public Health 1986; 76:515-8.

55 Chen Y, Li WX, Yu SZ, et al. Chang-Ning epidemiological study of children's health. I: Passive smoking and children's respiratory diseases. Int $\mathcal{F}$ Epidemiol 1988;17:348-55.

56 Jin C, Rossignol AM. Effects of passive smoking on respiratory illness from birth to age eighteen months, in Shanghai, People's Republic of China. F Pediatr 1993;123:553-8.

57 Chen Y. Environmental tobacco smoke, low birth weight, and hospitalization for respiratory disease. Am f Respir Crit Care Med 1994;150:54-8.

58 Martinez FD. Passive smoking and respiratory disorders other than cancer. In: The Report of the US Environmental Protection Agency, ed. Respiratory health effects of passive smoking: lung cancer and other disorders. US National Institute of Health, 1993: 205-65.

59 Registrar General. Mortality statistics: childhood, infant and perinatal. London: The Stationery Office, 1997.

60 Blair PS, Fleming PI, Bensley D, et al. Smoking and the sudden infant death syndrome: results from 1993-5 case-control study for confidential inquiry into stillbirths and deaths in infancy. Confidential Enquiry into Stillbirths and Deaths Regional Coordinators and Researchers. BMF 1996;313:195-8.

61 Department of Health. Hospital Episode Statistics. England 1994-5. (1). London: Department of Health, 1996.

62 Jarvis L. Smoking among secondary school children in 1996: England. London: The Stationery Office, 1998.

\section{Erratum}

The following errors appeared in the paper by Anderson HR, Cook DG. "Health effects of passive smoking. 2. Passive smoking and sudden infant death syndrome: review of the epidemiological evidence", Thorax 1997; 52:1003-1009.

In table 1, (i) the study by Bulterys et $a l^{30}$ is a duplicate of that by Kraus et $a l^{27}$ and should be deleted; (ii) the odds ratio for maternal prenatal smoking in the study by Malloy et $a l^{36}$ should have read 2.35 (not 3.25). To take account of the removal of the study by 
Bulterys and two minor errors table 2 has been updated below.

The paper by Strachan DP and Cook DG. "Health effects of passive smoking. 5. Parental smoking and allergic sensitisation in children", Thorax 1998;53:117-123, cited as reference 14 an abstract, which has subsequently been pub- lished in full as Ownby DR, Johnson CC, Peterson EL. "Maternal smoking does not influence cord serum $\operatorname{IgE}$ or $\operatorname{IgD}$ concentrations", $\mathcal{F}$ Allergy Clin Immunol 1991;88:555-560. The authors apologise for this oversight which does not affect the results or conclusions of the review.

Table 2 Summary of pooled odds ratios. Both fixed (FEM) and random (REM) effects models are shown

\begin{tabular}{|c|c|c|c|c|c|}
\hline Group of studies & Model & $\begin{array}{l}\text { Pooled unadjusted odds ratios } \\
(95 \% \text { CI) }\end{array}$ & Test for heterogeneity & $\begin{array}{l}\text { Pooled adjusted odds ratios } \\
(95 \% \mathrm{CI})\end{array}$ & Test for heterogeneity \\
\hline $\begin{array}{l}\text { Prenatal smoking } \\
\text { (all studies) }\end{array}$ & $\begin{array}{l}\text { REM } \\
\text { FEM }\end{array}$ & $\begin{array}{l}2.74(2.42 \text { to } 3.10)(\mathrm{n}=33) \\
2.74(2.59 \text { to } 2.90)\end{array}$ & $\chi^{2}(\mathrm{df}=32)=120.7(\mathrm{p}<0.001)$ & $\begin{array}{l}2.13(1.86 \text { to } 2.43)(\mathrm{n}=18) \\
2.17(2.04 \text { to } 2.31)\end{array}$ & $\chi^{2}(\mathrm{df}=17)=54.0(\mathrm{p}<0.001)$ \\
\hline $\begin{array}{l}\text { Prenatal smoking, studies } \\
\text { with information on } \\
\text { non-adjusted and } \\
\text { adjusted odds ratios }\end{array}$ & $\begin{array}{l}\text { REM } \\
\text { FEM }\end{array}$ & $\begin{array}{l}2.82(2.38 \text { to } 3.33)(\mathrm{n}=15) \\
2.89(2.70 \text { to } 3.09)\end{array}$ & $\chi^{2}(\mathrm{df}=14)=59.1(\mathrm{p}<0.001)$ & $\begin{array}{l}2.18(1.89 \text { to } 2.51)(\mathrm{n}=15) \\
2.20(2.05 \text { to } 2.36)\end{array}$ & $\chi^{2}(\mathrm{df}=14)=40.7(\mathrm{p}<0.001)$ \\
\hline $\begin{array}{l}\text { Prenatal smoking (cohort } \\
\text { studies) }\end{array}$ & $\begin{array}{l}\text { REM } \\
\text { FEM }\end{array}$ & $\begin{array}{l}2.75(1.97 \text { to } 3.82)(\mathrm{n}=7) \\
2.39(2.15 \text { to } 2.65)\end{array}$ & $\chi^{2}(\mathrm{df}=6)=22.2(\mathrm{p}=0.001)$ & $\begin{array}{l}(\mathrm{n}=4)^{\star} \\
2.04(1.84 \text { to } 2.25)\end{array}$ & $\chi^{2}(\mathrm{df}=3) 14.5(\mathrm{p}=0.002)$ \\
\hline $\begin{array}{l}\text { Prenatal smoking } \\
\quad \text { (case-control studies) }\end{array}$ & $\begin{array}{l}\text { REM } \\
\text { FEM }\end{array}$ & $\begin{array}{l}2.73(2.37 \text { to } 3.16)(\mathrm{n}=26) \\
2.89(2.71 \text { to } 3.09)\end{array}$ & $\chi^{2}(\mathrm{df}=25)=78.8(\mathrm{p}<0.001)$ & $\begin{array}{l}2.22(1.88 \text { to } 2.61)(\mathrm{n}=14) \\
2.26(2.09 \text { to } 2.45)\end{array}$ & $\chi^{2}(\mathrm{df}=13) 37.0(\mathrm{p}<0.001)$ \\
\hline Postnatal smoking & $\begin{array}{l}\text { REM } \\
\text { FEM }\end{array}$ & $\begin{array}{l}2.80(2.00 \text { to } 3.93)(n=9) \\
3.10(2.70 \text { to } 3.56)\end{array}$ & $\chi^{2}(\mathrm{df}=8)=35.0(\mathrm{p}<0.001)$ & $\begin{array}{l}(\mathrm{n}=4)^{\star} \dagger \\
1.94(1.55 \text { to } 2.43)\end{array}$ & $\chi^{2}(\mathrm{df}=3)=1.18(\mathrm{p}=0.76)$ \\
\hline
\end{tabular}

Schoendorf study results ${ }^{37}$ were analysed separately for black and white subjects and in all these analyses are counted as two separate studies. $\star$ Below the minimum of five studies for estimation of random effects.

†Excludes reference 46 which did not control for prenatal smoking. 